\title{
Uso de Argila Organofílica na Compatibilização de Misturas PP/EPDM
}

\author{
Kaline R. M. Ferreira \\ Programa de Pós-Graduação em Ciência e Engenharia de Materiais, UFCG \\ Itamara F. Leite \\ Departamento de Engenharia de Materiais, UFPB \\ Alex da S. Siqueira \\ Universidade Estadual da Zona Oeste, UEZO \\ Claudia M. 0. Raposo \\ Unidade Acadêmica de Mineração e Geologia, UFCG \\ Laura H. Carvalho, Suédina M. L. Silva \\ Unidade Acadêmica de Engenharia de Materiais, UFCG
}

\begin{abstract}
Resumo: Misturas PP/EPDM com variadas razões PP:EPDM, não compatibilizadas e compatibilizadas com o polipropileno modificado com anidrido maleico (PP-g-MA), foram preparadas por fusão. A influência da adição de 1 pcr de uma argila bentonita na morfologia, propriedades mecânicas e reológicas destas misturas foi avaliada. A bentonita empregada como carga, proveniente da Bentonit União Nordeste/PB foi purificada e modificada organicamente com tecnologia desenvolvida por nosso grupo de pesquisa, antes de ser adicionada às misturas. Os dados de difratometria de raios X mostraram que, para diferentes razões de PP:EPDM na mistura a incorporação de 1 pcr de argila organofílica resultou na formação de nanocompósitos intercalados desordenados (20 ou 40\% de EPDM) ou intercalados/ esfoliados (10 e 30\% EPDM). A incorporação da argila organofílica provocou alterações nas propriedades morfológicas, mecânicas e reológicas das misturas, especialmente daquelas preparadas com 30\% em massa de EPDM onde a ação compatibilizante da argila foi observada.
\end{abstract}

Palavras-chave: Blendas PP/EPDM, argila organofílica, compatibilização.

\section{The Use of an Organoclay on the Compatibilization of PP/EPDM Blends}

Abstract: PP/EPDM blends with different PP:EPDM ratios, non-compatibilized and compatibilized with maleic anhydride grafted polypropylene (PP-g-MA) were prepared by melting. The influence of $1 \mathrm{phr}$ bentonite clay addition on the morphology, mechanical and rheological properties of these blends was evaluated. The bentonite used as a filler, provided by Bentonit União Nordeste/PB, was purified and organically modified with a technology developed by our research group, before being added to the blends. X-ray diffraction results showed that, for blends having different PP:EPDM ratios, 1 phr organoclay addition led to the formation of intercalated (20 or $40 \%$ EPDM) or intercalated/exfoliated (10 and 30\% EPDM) nanocomposites. The morphological, mechanical and rheological properties of the blends were modified by organoclay addition, especially for those with $30 \mathrm{wt} \%$ of EPDM, where a compatibilizing effect of the organoclay was observed.

Keywords: PP/EPDM blends, organoclay, compatibilization.

\section{Introdução}

O desenvolvimento de misturas (blendas) poliméricas é de grande interesse acadêmico e industrial por ser uma prática relativamente simples de criar materiais com propriedades desejadas ${ }^{[1,2]}$. A mistura de polipropileno (PP) com elastômeros visa melhorar sua resistência ao impacto (tenacidade) a baixas temperaturas. Vários elastômeros são usados como modificadores de impacto para o PP, incluindo poliisobutileno ${ }^{[3]}$, copolímero em bloco de estireno-butadieno ${ }^{[4]}$, poliisopreno ${ }^{[5]}$ e borracha natural ${ }^{[6]}$, mas os copolímeros de etileno-propileno (EPR) ${ }^{[7]}$ e os terpolímeros de etileno-propileno-dieno (EPDM) $)^{[8-11]}$ têm sido mais eficientes para esta aplicação.

Estudos reportados na literatura têm mostrado que a incorporação do EPDM ao PP resulta na obtenção de PP tenacificado, também denominado poliolefina termoplástica
(TPO). Contudo, algumas propriedades mecânicas do PP, tais como dureza e rigidez são notavelmente reduzidas o que limita o campo de aplicação destes materiais ${ }^{[12]}$. Visando, portanto, conseguir um ótimo balanço de propriedades (tenacidade e dureza), cargas convencionais como talco e fibras de vidro têm sido incorporadas as poliolefinas termoplásticas (TPOs), produzindo compósitos ternários ${ }^{[13]}$. Devido ao tamanho ou razão de aspecto de tais cargas, grandes quantidades (>20\% em massa) são requeridas para se atingir as propriedades desejadas o que dificulta o processamento e resulta em materiais mais densos. A substituição de tais cargas por pequenas quantidades ( $<5 \%$ em massa) de argilas organofílicas permite aumentos na dureza (módulo) do TPO comparável ao PP carregado com $30-40 \%$ de talco quando dispersas na matriz polimérica em escala nanométrica ${ }^{[14]}$.

Autor para correspondência: Suédina M. de L. Silva, Unidade Acadêmica de Engenharia de Materiais, Universidade Federal de Campina Grande, Av. Aprígio Veloso, 882, Bairro Universitário, CEP 58429-140, Campina Grande, PB, Brasil, e-mail: suedina@dema.ufcg.edu.br 
Níveis muito baixos de carga (1-5\%) em nanocompósitos a base de TPOs (nano-TPO) possibilita o processamento em temperaturas mais baixas o que diminui o tempo de ciclo, além disso, os TPOs na forma de nanocompósitos apresentam dureza equivalente aos carregados com talco, porém são mais leves (baixa gravidade especifica), apresentam melhor resistência ao impacto a baixas temperaturas e uma melhor qualidade superficial das peças moldadas (superfícies com tato aveludado), maior resistência ao risco e maior temperatura de distorção térmica (HDT) ${ }^{[15]}$. Isto possibilita a utilização dos nano-TPOs na indústria automobilística, podendo substituir outros termoplásticos de engenharia para melhorar o processamento bem como a reciclabilidade ${ }^{[16]}$. Embora nanocompósitos a base de TPO (PP/EPDM) tenham sido preparados com sucesso por muitos grupos ${ }^{[17-23]}$ as propriedades dos nano-TPOs são altamente dependentes de fatores como: tipo dos componentes, composição da mistura (razão de PP e EPDM) e, principalmente, tipo e teor de argila organofílica, bem como do grau de dispersão e de interação química desta com a matriz polimérica. Portanto, neste estudo foi avaliado o efeito de uma argila bentonita, proveniente de indústria local, na morfologia e propriedades mecânicas de misturas PP/EPDM (poliolefinas termoplásticas-TPOs), preparadas com variadas razões PP:EPDM, não compatibilizadas e compatibilizadas com polipropileno modificado com anidrido maleico (PP-g-MA).

\section{Experimental}

\section{Materiais}

O polipropileno isotático - PP H103 - (índice de fluidez de $40 \mathrm{dg}$ / min a $230{ }^{\circ} \mathrm{C} / 2,16 \mathrm{Kg}$ e densidade de $0,905 \mathrm{~g} . \mathrm{cm}^{-3}$ ), fornecido pela Braskem/Brasil e o terpolímero de etileno-propileno-dieno - EPDM de nome comercial Keltan 3200A (49\% de etileno e viscosidade Mooney 51, ML $(1+4)$ a $\left.125^{\circ} \mathrm{C}\right)$, fornecido pela DSM Elastomers Brazil/São Paulo, foram usados na preparação das blendas. O compatibilizante, polipropileno modificado anidrido maleico (PPg-MA), Polybond 3200, com $1 \%$ em massa de anidrido maleico (índice de fluidez de $115 \mathrm{~g} / 10 \mathrm{~min}$ a $190{ }^{\circ} \mathrm{C} / 2,16 \mathrm{Kg}$; densidade de $0,91 \mathrm{~g} \cdot \mathrm{cm}^{-3}$ e temperatura de fusão de $160-170{ }^{\circ} \mathrm{C}$ ) foi fornecido pela Crompton Corporation/USA.

A bentonita Argel 35 (AN) com capacidade de troca catiônica (CTC) de 0,92 meq/g de argila, conforme determinada previamente ${ }^{[24]}$, foi fornecida pela Bentonit União Nordeste (BUN-Campina Grande/ Brasil). Esta argila foi purificada, visando à remoção de matéria orgânica, de acordo com procedimento reportado por Araújo et al. $(2007)^{[25]}$ e, codificada como AP. O surfactante brometo de cetil trimetil amônio, $\mathrm{C}_{16} \mathrm{H}_{33}\left(\mathrm{CH}_{3}\right)_{3} \mathrm{~N}^{+} \mathrm{Br}$, fornecido pela Vetec, foi usado como recebido na modificação orgânica da argila AP. A argila modificada organicamente com tecnologia nacional ${ }^{[26]}$ foi codificada como APO.

\section{Preparação das amostras}

As misturas PP/EPDM, PP/EPDM//PP-g-MA, PP/EPDM/APO e PP/EPDM/PP-g-MA/APO foram preparadas em um misturador interno Haake Rheomix 600, operando com rotores do tipo roller a $180{ }^{\circ} \mathrm{C}$ e $50 \mathrm{rpm}$ por 15 minutos. As composições estudadas estão apresentadas na Tabela 1. A quantidade de argila organofílica (APO) empregada na preparação das misturas foi de 1 parte por cem de resina (1 pcr) em relação a quantidade de EPDM e, a quantidade de PP-g-MA foi de três vezes a quantidade de argila, correspondente a uma razão PP-g-MA:APO de 3:1. Antes da mistura o PP-g-MA foi seco em uma estufa a vácuo a $80{ }^{\circ} \mathrm{C}$ por 24 horas.

\section{Caracterização das Amostras}

\section{Difratometria de raios $X(D R X)$}

As medidas de DRX foram conduzidas à temperatura ambiente em um equipamento Shimadzu XRD-6000, utilizando radiação Cuk $\alpha(\lambda=1,5418 \AA$ A), tensão de $40 \mathrm{kV}$, corrente de $30 \mathrm{~mA}$. As misturas foram examinadas em um intervalo de $2 \theta$ entre 2 e $12^{\circ}$ e velocidade de varredura de $2 \% \mathrm{~min}$. Corpos de prova com espessura média de $1,0 \mathrm{~mm}$, moldados por compressão a $180^{\circ} \mathrm{C}$, foram usados para esta caracterização.

\section{Microscopia eletrônica de varredura (MEV)}

As superfícies de fratura das misturas foram observadas em um microscópio eletrônico de varredura JEOL T330A. As amostras foram fraturadas em nitrogênio líquido e as superfícies de fratura recobertas com uma fina camada de ouro antes de serem analisadas.

\section{Propriedades mecânicas}

As misturas foram caracterizadas por ensaio de tração de acordo com a norma da ASTM D882. Os testes foram conduzidos a temperatura ambiente em uma máquina EMIC com célula de carga de $20 \mathrm{~N}$ e velocidade de afastamento das garras de $5 \mathrm{~mm} / \mathrm{min}$. Uma média de 5 corpos de prova foi empregada para cada composição.

Tabela 1. Composição das amostras.

\begin{tabular}{|c|c|c|c|c|c|c|}
\hline Amostra & Código & Proporção PP/EPDM & $\mathbf{P P}(\mathrm{g})$ & EPDM (g) & PP-g-MA (g) & APO (g) \\
\hline \multirow{4}{*}{ PP/EPDM } & PE91 & $90 / 10$ & 45 & 5 & - & - \\
\hline & PE82 & $80 / 20$ & 40 & 10 & - & - \\
\hline & PE73 & $70 / 30$ & 35 & 15 & - & - \\
\hline & PE64 & $60 / 40$ & 30 & 20 & - & - \\
\hline \multirow{4}{*}{ PP/EPDM/PP-g-MA } & PEP91 & $90 / 10$ & 45 & 5 & 0,15 & - \\
\hline & PEP82 & $80 / 20$ & 40 & 10 & 0,30 & - \\
\hline & PEP73 & $70 / 30$ & 35 & 15 & 0,45 & - \\
\hline & PEP64 & $60 / 40$ & 30 & 20 & 0,60 & - \\
\hline \multirow{4}{*}{ PP/EPDM/APO } & PEA91 & $90 / 10$ & 45 & 5 & - & 0,05 \\
\hline & PEA82 & $80 / 20$ & 40 & 10 & - & 0,10 \\
\hline & PEA73 & $70 / 30$ & 35 & 15 & - & 0,15 \\
\hline & PEA64 & $60 / 40$ & 30 & 20 & - & 0,20 \\
\hline \multirow{3}{*}{ PP/EPDM/ PP-g-MA/APO } & PEPA91 & $90 / 10$ & 45 & 5 & 0,15 & 0,05 \\
\hline & PEPA73 & $70 / 30$ & 35 & 15 & 0,45 & 0,15 \\
\hline & PEPA64 & $60 / 40$ & 30 & 20 & 0,60 & 0,20 \\
\hline
\end{tabular}




\section{Reometria de placas paralelas}

O comportamento reológico das misturas foi avaliado em reômetro de placas paralelas da empresa Haake (MARS) nas seguintes condições: temperatura de análise de $190{ }^{\circ} \mathrm{C}$, diâmetro da placa superior de $25 \mathrm{~mm}$ e distância entre as placas de $1 \mathrm{~mm}$. Os testes foram realizados em triplicatas, sendo apresentado o valor médio para cada ponto analisado. Ensaios de varredura de deformação foram realizados na faixa de 0,1 a $500 \%$, e os ensaios de varredura de frequência de 0,628 a $628 \mathrm{rad} / \mathrm{s}$.

\section{Resultados e Discussão}

\section{Difratometria de raios $X(D R X)$}

Os difratogramas de raios $\mathrm{X}$ das misturas $\mathrm{PP} / \mathrm{EPDM}$, com razões de PP para EPDM correspondentes a 90:10; 80:20; 70:30 e 60:40 não compatibilizadas (PE91, PE82, PE73 e PE64) e compatibilizadas com PP-g-MA (PEP91, PEP82, PEP73 e PEP64), estão mostrados na Figura 1. Conforme esperado, não se observa picos para nenhuma destas misturas na faixa de $2 \theta$ estudado (de 1,5 a $12^{\circ}$ ). Por outro lado, quando a argila organofílica APO foi incorporada as misturas PE82, PE73 e PE64 não compatibilizadas (Figura 2a), à distância interplanar basal da mesma aumentou de $1,9 \mathrm{~nm}\left(2 \theta=4,6^{\circ}\right)$ para

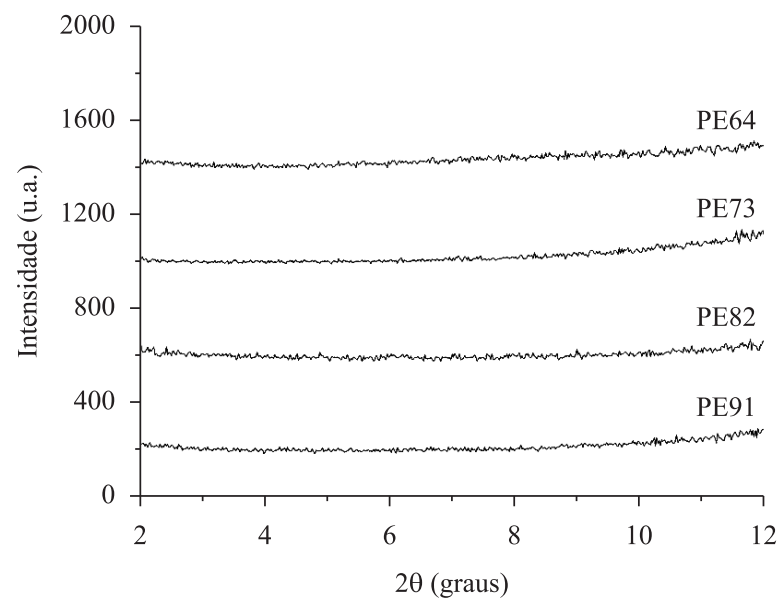

(a) aproximadamente $3,9 \mathrm{~nm}\left(2 \theta=2,3^{\circ}\right)$, devido à penetração de cadeias poliméricas dentro da região interlamelar da argila. Os picos registrados para estas misturas (PEA82, PEA73 e PEA64) são bem alargados e de baixa intensidade, sugerindo a extensiva penetração do polímero e formação de nanocompósitos intercalados desordenados. Para a mistura PEA91, o pico correspondente a reflexão basal (001) da argila APO não foi observado. É possível que neste caso, nanocompósito predominantemente esfoliado tenha sido formado, pois a ausência de pico em um difratograma, correspondente a reflexão basal (001) da argila no polímero, sugere que as camadas de argila estão delaminadas e aleatoriamente dispersas na matriz polimérica ${ }^{[27]}$.

A Figura $2 b$ mostra os difratogramas de raios $\mathrm{X}$ das misturas PP/EPDM/APO compatibilizadas com PP-g-MA (PEPA91, PEPA82, PEPA73 e PEPA64). Os difratogramas destas misturas foram semelhantes aos das misturas não compatibilizadas (PEA91, PEA82, PEA73 e PEA64) (Figura 2a). Observa-se a presença de picos alargados e de baixa intensidade para as misturas PEPA82 e PEPA64, em torno de $3,9 \mathrm{~nm}\left(2 \theta=2,3^{\circ}\right)$ correspondentes a reflexão basal (001) da argila APO, sugerindo a formação de nanocompósitos intercalados desordenados. Para a mistura PEPA91 o pico 001 está deslocado para valores de $2 \theta$ inferiores a $2,3^{\circ}$ (distância interplanar basal superior a 3,9 nm) sugerindo a obtenção de um nanocompósito

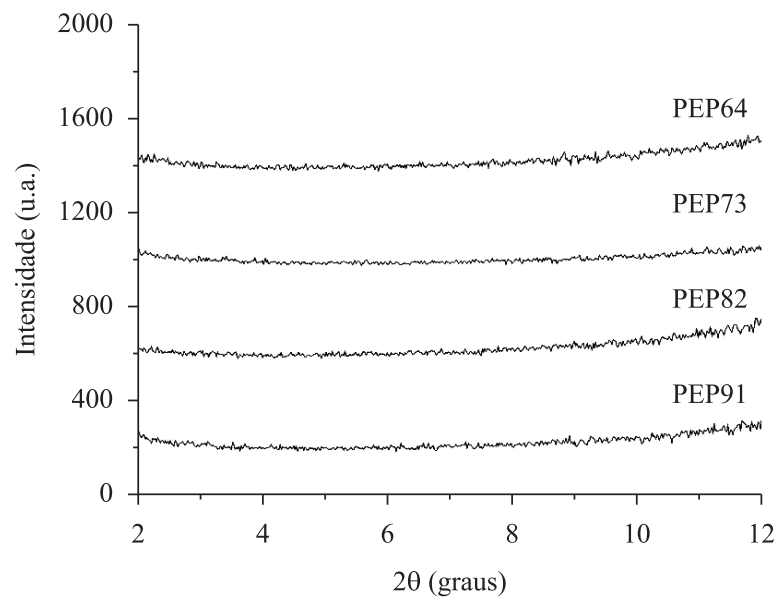

(b)

Figura 1. Difratogramas das misturas PP/EPDM a) não compatibilizadas; e b) compatibilizadas com PP-g-MA.

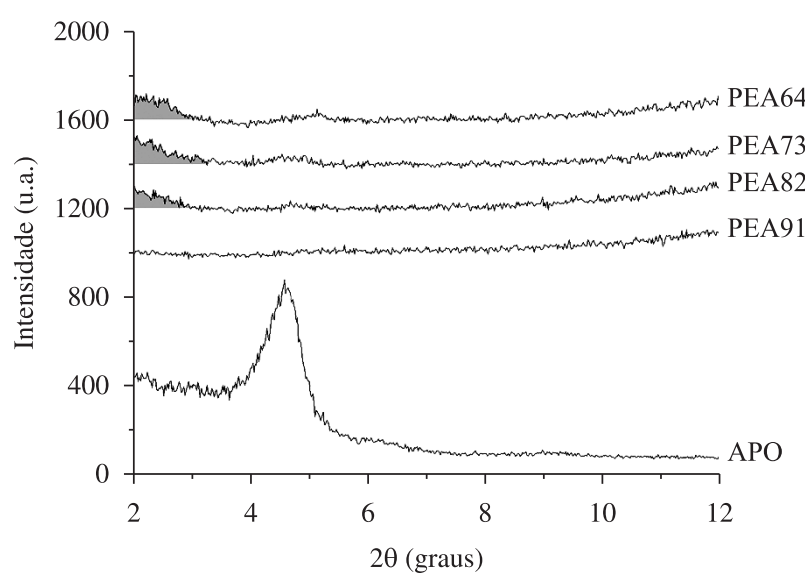

(a)

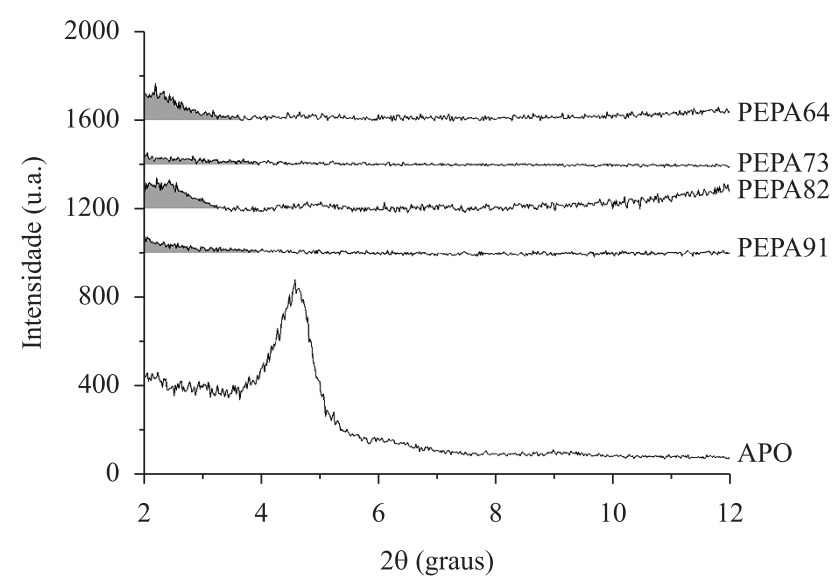

(b)

Figura 2. Difratogramas da argila organofílica APO e das misturas a) PP/EPDM/APO; e b) PP/EPDM/PP-g-MA/APO. 
com estrutura mais desordenada do que às apresentadas pelas misturas PEPA82 e PEPA64. Para a mistura PEPA73, praticamente, não se observa pico na faixa de $2 \theta$ estudado, indicando a possível obtenção de um nanocompósito predominantemente esfoliado.

Segundo a literatura ${ }^{[28]}$, as propriedades mecânicas dos nanocompósitos são significativamente melhoradas quando partículas de argila estão esfoliadas na matriz polimérica e quando uma boa afinidade entre as fases é atingida. Por esta razão, as propriedades mecânicas das misturas com morfologias predominantemente esfoliada ou intercalada/desordenada foram avaliadas (PEPA91, PEPA73, PEA91 e PEA73), conforme difratogramas mostrados na Figura 2.

\section{Propriedades mecânicas}

Nas Figuras 3, 4 e 5 estão reportados os valores de módulo de elasticidade, resistência à tração e alongamento na ruptura das misturas PP/EPDM (PE), PP/EPDM/APO (PEA) e PP/EPDM/PPg-MA/APO (PEPA), com razões de PP:EPDM correspondentes a 90:10 e 70:30.

Comparando as misturas de PEA91 e PEA73 com as misturas PE91 e PE73, observa-se que as misturas contendo 1 pcr de APO apresentaram aumentos de aproximadamente 21 e $61 \%$ nos valores

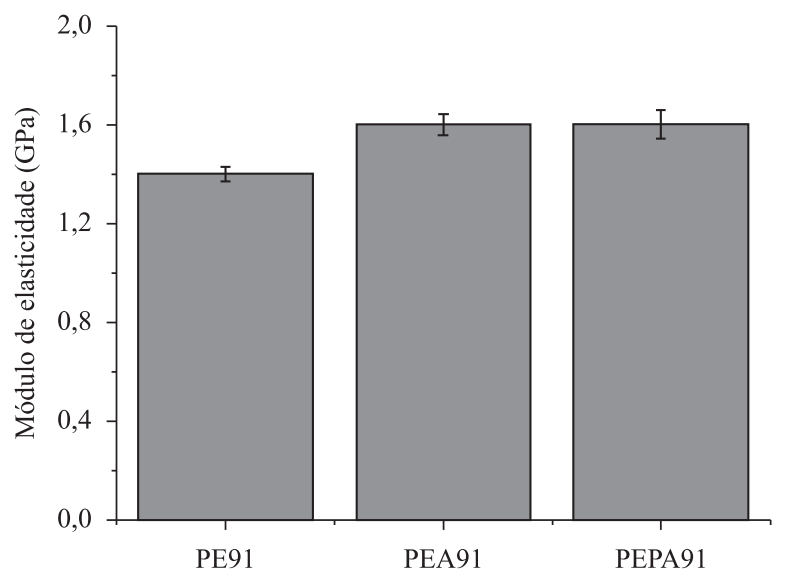

(a) de resistência à tração; de 14 e $36 \%$ nos valores de módulo de elasticidade e de 67 e $91 \%$ nos valores de alongamento na ruptura, respectivamente. Como os maiores aumentos nos valores das propriedades mecânicas foram registrados para a mistura PEA73, é possível que nesta mistura, a argila organofílica APO tenha atuado de forma mais efetiva como compatibilizante na interface dos dois polímeros, limitando a segregação de fases durante a etapa de mistura e, resultando em uma fina dispersão de fases ou em um aumento no grau de continuidade da fase EPDM na matriz de $\mathrm{PP}^{[29,30]}$. Para confirmar esta suposição, análises de microscopia eletrônica de varredura (MEV) foram realizadas e os resultados obtidos estão mostrados na Figura 6.

As propriedades mecânicas das misturas, PEPA91 e PEPA73, preparadas com a adição conjunta de PP-g-MA e APO também estão mostradas nas Figuras 3, 4, e 5. Estas misturas também apresentaram propriedades mecânicas superiores às das misturas PE91 e PE73 e quando comparadas com as misturas PEA91 e PEA73, verifica-se que os valores de módulo de elasticidade e de resistência à tração destas misturas são semelhantes ou ligeiramente inferiores aos das misturas PEA91 e PEA73. Por outro lado, os valores de alongamento na ruptura das misturas PEPA91 e PEPA73 são ligeiramente superiores aos das misturas PEA91 e PEA73. Os maiores valores desta propriedade para as misturas PEPA91 e

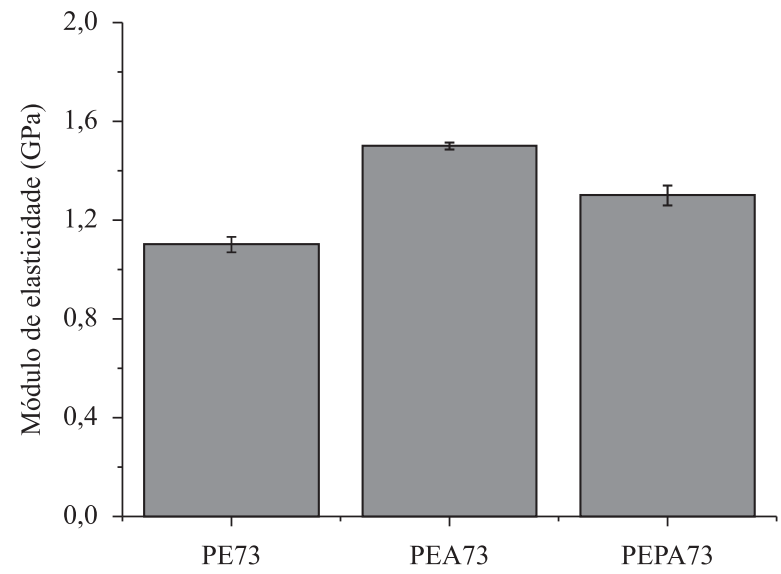

(b)

Figura 3. Módulo de elasticidade das misturas PP/EPDM (PE), PP/EPDM/APO (PEA) e PP/EPDM/PP-g-MA/APO (PEPA), com razões de PP:EPDM correspondentes a: a) 90:10; e b) 70:30.

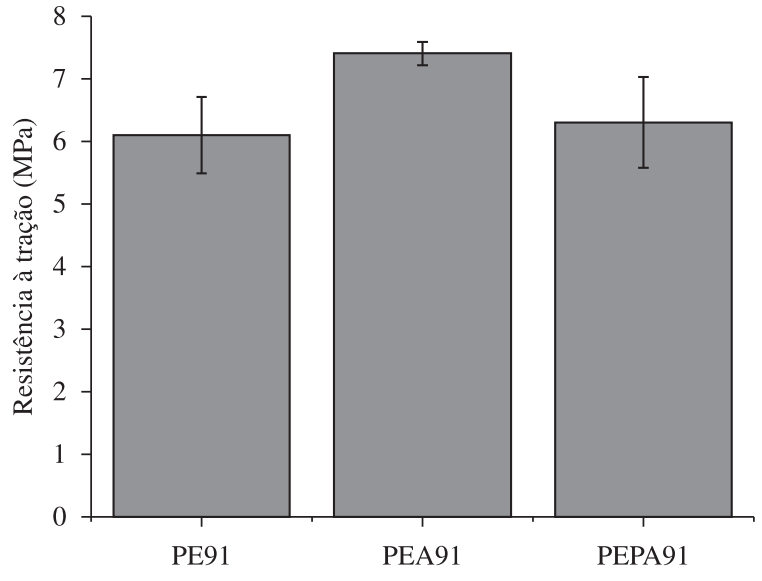

(a)

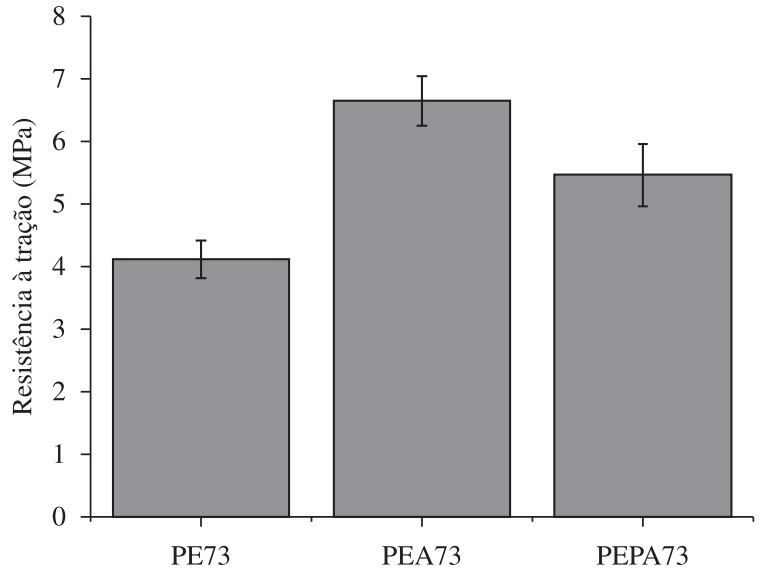

(b)

Figura 4. Resistência à tração das misturas PP/EPDM (PE), PP/EPDM/APO (PEA) e PP/EPDM/PP-g-MA/APO (PEPA), com razões de PP:EPDM correspondentes a: a) 90:10; e b) 70:30. 


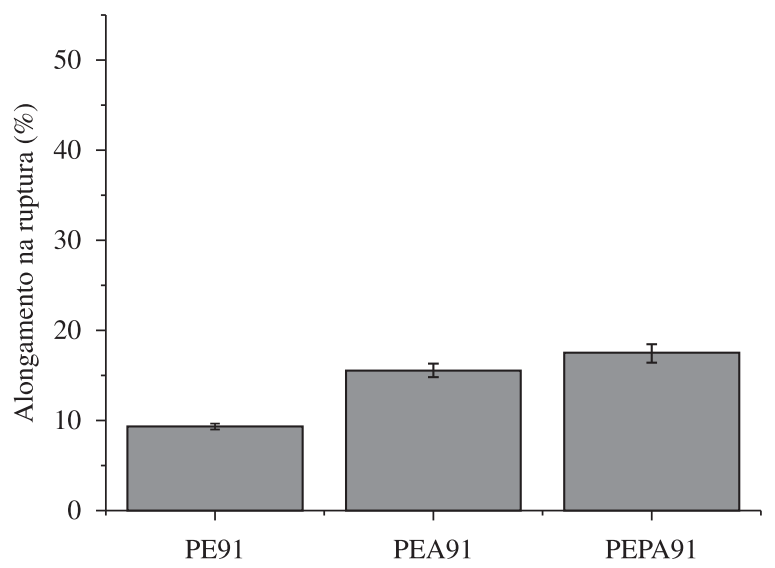

(a)

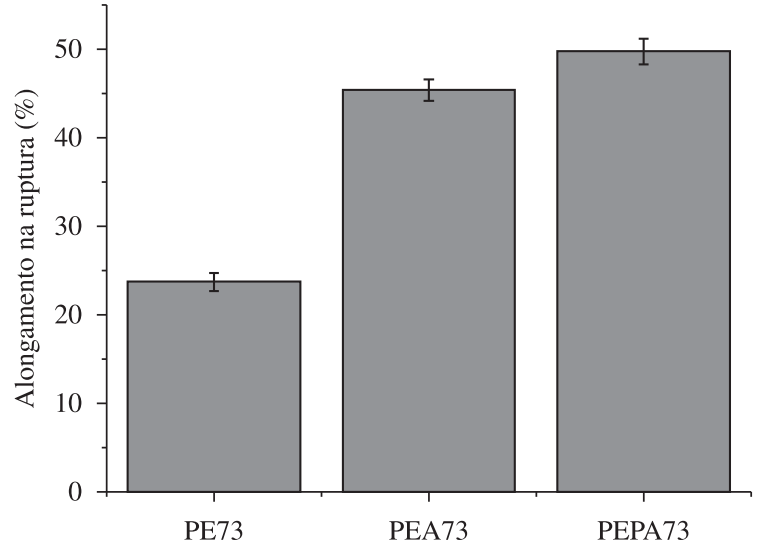

(b)

Figura 5. Alongamento na ruptura das misturas PP/EPDM (PE), PP/EPDM/APO (PEA) e PP/EPDM/PP-g-MA/APO (PEPA), com razões de PP:EPDM correspondentes a: a) 90:10; e b) 70:30.

PEPA73 sugerem uma maior compatibilização das misturas PP/ EPDM quando preparadas na presença dos dois componentes (PPg-MA e APO), uma vez que o alongamento na ruptura tem alta sensibilidade a variações estruturais e morfológicas de materiais ${ }^{[30]}$.

Os valores de resistência à tração e de módulo de elasticidade da mistura PP/EPDM contendo 30\% em massa de EPDM e 1 pcr de APO (PEA73) foram semelhantes aos da mistura PP/EPDM contendo apenas 10\% em massa de EPDM (PE91). Entretanto, o alongamento na ruptura da mistura PEA73 foi consideravelmente superior. Com base nesses resultados fica evidenciado que a incorporação de apenas 1 pcr da argila organofílica APO às misturas PP/EPDM promoveu a tenacificação do PP sem comprometer a sua rigidez.

\section{Microscopia eletrônica de varredura (MEV)}

As micrografias de MEV das misturas PE, PEA e PEPA, com razões de PP:EPDM correspondentes a 90:10 e 70:30, estão mostradas na Figura 6. As misturas PE91 e PE73 exibiram uma morfologia globular típica de blendas imiscíveis, com gotículas esféricas da fase EPDM dispersa na matriz PP (Figuras 6a,b). A presença de vazios indica que a adesão interfacial é fraca para ambas as amostras ${ }^{[31]}$. A morfologia da mistura PEA91 (Figura 6c) é semelhante a da mistura PE91 (Figura 6a), indicando que a incorporação de argila organofílica APO praticamente não afetou o tamanho e a forma da fase dispersa. Por outro lado, a morfologia da mistura PEA73 (Figura 6d) exibiu uma extensão considerável de continuidade de fase, morfologia elipsoidal, significando que a forma irregular da fase dispersa, promovida pela carga APO resultou em um maior grau de interpenetração das fases. Comportamento semelhante foi reportado na literatura ${ }^{[32]}$

A mistura PEPA91 (Figura 6e), mistura contendo PP-g-MA e APO, apresentou uma fase dispersa com menor tamanho de partícula e com uma menor quantidade de vazios quando comparada com a mistura PEA91 (Figura 6c), indicando que a mistura PP-g-MA/APO impede a coalescência e aglomeração das partículas de EPDM. Isto era esperado, uma vez que o PP-g-MA promove a compatibilização das fases constituintes, possibilitando uma maior interação entre as ambas as fases e, consequentemente, uma redução no tamanho da fase dispersa ${ }^{[1]}$.

A morfologia da mistura PEPA73 (Figura 6f) também foi afetada com a presença da mistura PP-g-MA/APO; a morfologia elipsoidal da fase dispersa EPDM mudou para esférica e os tamanhos das partículas foram inferiores aos observados para a mistura PE73 (Figura 6b). Isto indica um aumento na interação interfacial entre as duas fases.
Os resultados de MEV evidenciam o papel fundamental da argila organofílica APO em promover mudanças significativas na morfologia da mistura PE73 e, como consequência nas propriedades mecânicas da mesma. Evidenciam também o aumento na compatibilização dos componentes poliméricos quando as misturas foram preparadas na presença de PP-g-MA/APO (misturas PEPA). Os resultados de viscosidade complexa mostrados na Figura 7 e Tabela 2 corroboram estas observações.

Com base no exposto, o controle da morfologia e do comportamento da fase dispersa torna-se um fator chave na determinação do desempenho de blendas poliméricas, que depende principalmente da interface entre os componentes poliméricos. De acordo com a literatura ${ }^{[33-43]}$ argilas organofílicas podem reduzir o tamanho dos domínios da fase dispersa de blendas poliméricas desde que sejam intercaladas ou esfoliadas em pelo menos um dos componentes da blenda polimérica. Conforme reportado ${ }^{[44,45]}$, enxertos formados in situ, durante o processo de mistura por fusão de blendas poliméricas/argilas organofílicas, podem ter a mesma função dos copolímeros em bloco, diminuindo eficientemente a tensão interfacial e reduzindo o tamanho dos domínios da fase dispersa.

\section{Reometria de placas paralelas}

Os gráficos de varredura de deformação das misturas PE, PEA e PEPA, com razões de PP:EPDM correspondentes a 90:10 e 70:30, estão apresentados na Figuras 7. Nota-se que na região de viscoelasticidade linear (reta paralela ao eixo da deformação) as misturas PEA e PEPA apresentaram valores de viscosidade complexa superiores aos da mistura PE nas composições estudadas. Em primeira análise este comportamento indica que a presença da argila dificulta o fluxo do material. As misturas PEA73 e PEPA73 apresentaram a maior diferença de viscosidade em relação à mistura PE. Este comportamento foi atribuído ao efeito modificador da argila. O aumento no valor da viscosidade complexa para a mistura PEPA91 pode ser atribuído a presença de agente compatibilizante PP-g-MA, o que aumenta a interação entre a argila e a matriz polimérica. Os resultados das propriedades mecânicas corroboram este comportamento.

A análise de varredura de frequência das misturas foi realizada com deformação de $1 \%$, região linear da viscoelasticidade. O comportamento dos materiais no ponto de cruzamento, determinado quando os valores dos módulos são iguais $\left(G^{\prime}=G^{\prime \prime}\right)$, fornece resultados importantes sobre a estrutura do polímero, massa molar 
e distribuição de massa molar. De acordo com a Tabela 2, as frequências de cruzamento das misturas PEA73 e PEPA73 foram inferiores a da mistura PE73, sendo a maior redução apresentada pela última, indicando que neste caso a interação entre as fases PP e EPDM foi maior. Para a mistura PEA91 não houve redução no valor de frequência quando comparada com a mistura PE91. Este comportamento sugere que para esta composição a argila APO não atuou como compatibilizante. Por outro lado, a frequência foi reduzida para a mistura PEPA91, indicando que para a mistura PE91 a compatibilização se deu apenas com a incorporação de ambos os componente (PP-g-MA + APO), conforme sugere os resultados das propriedades mecânicas e de MEV.

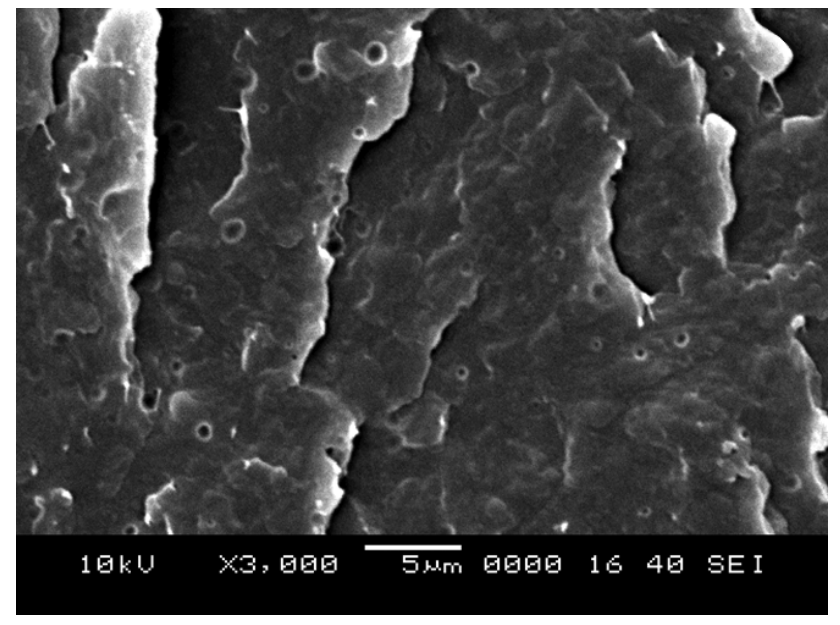

(a)

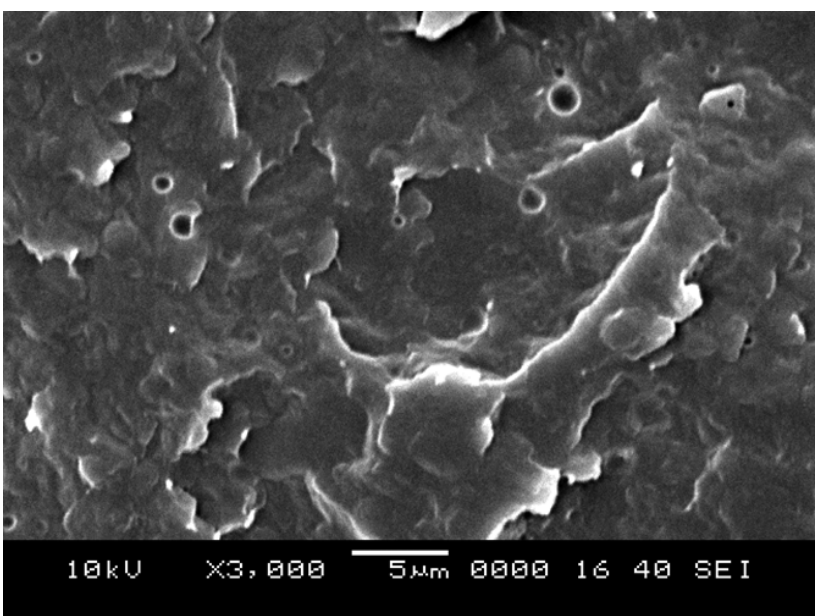

(c)

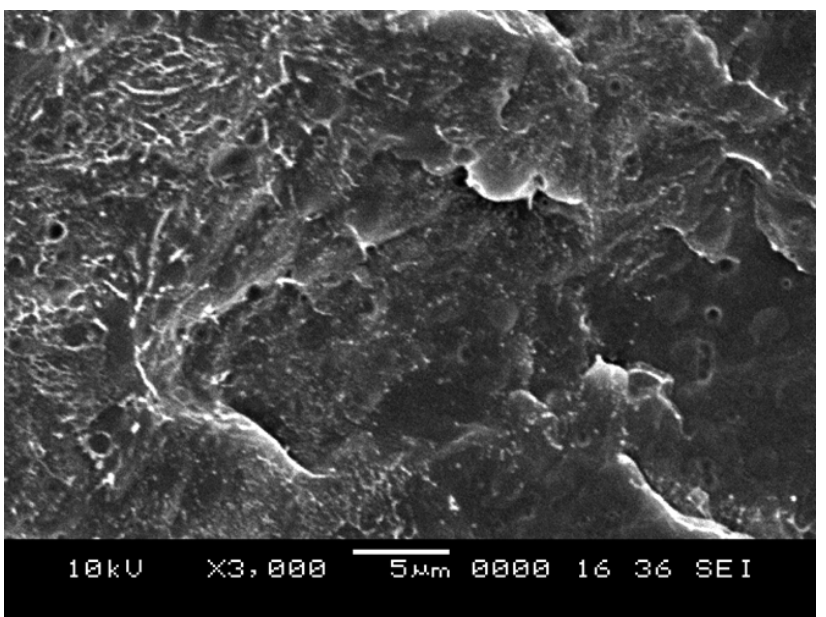

(e)

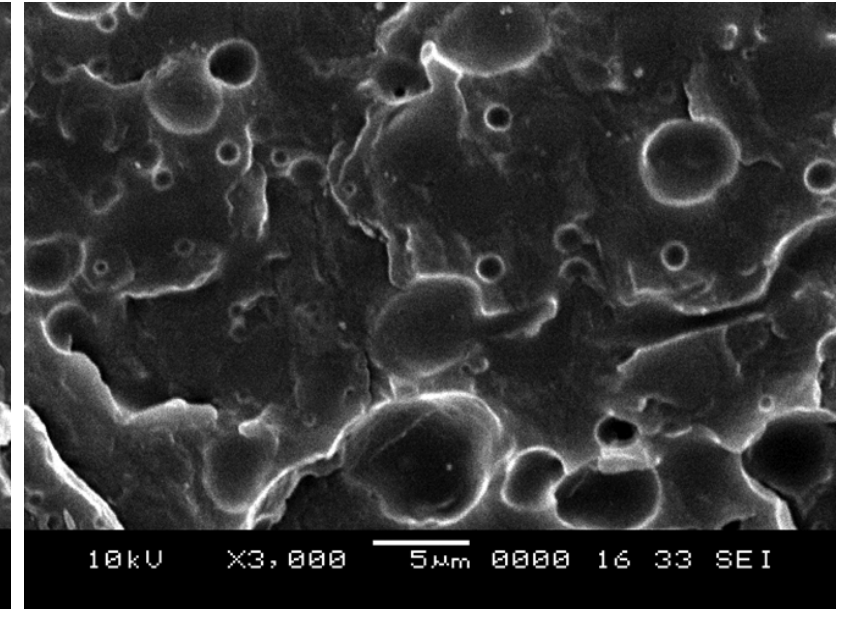

(b)

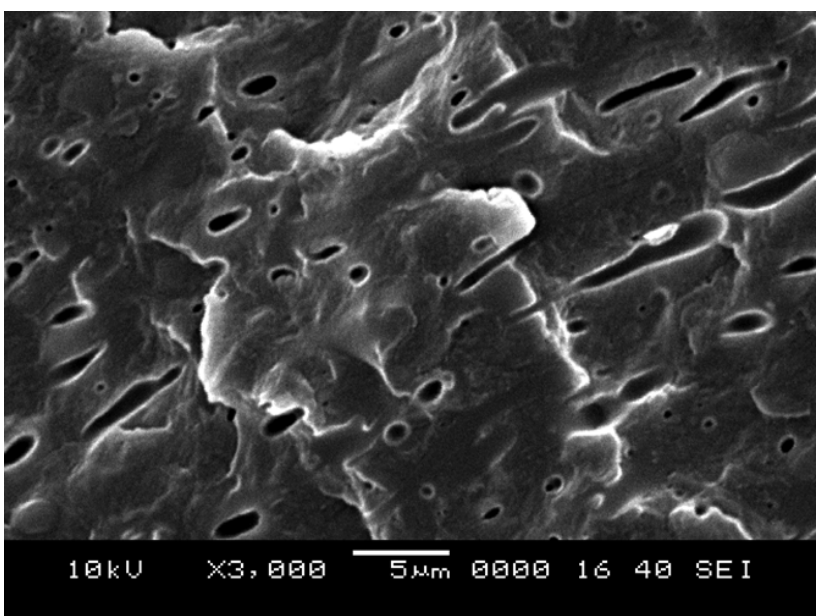

(d)

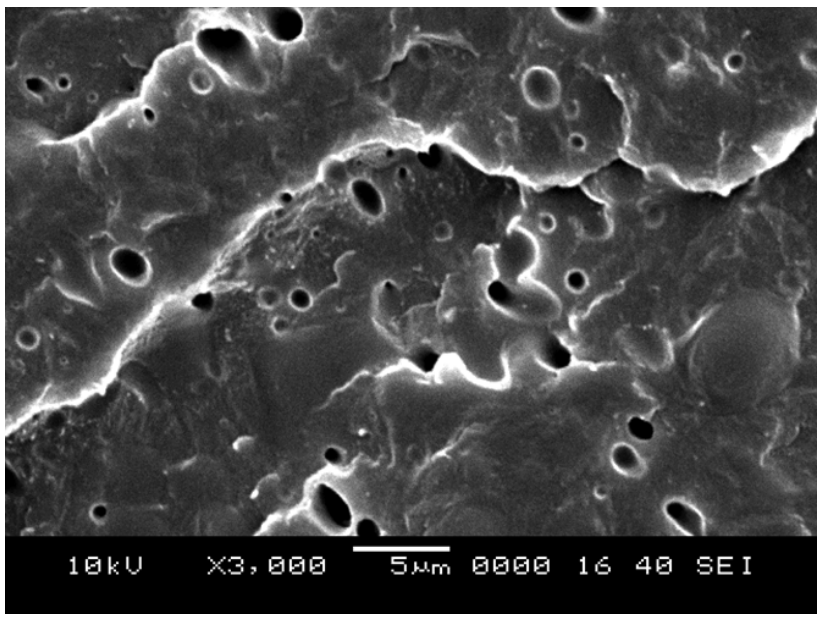

(f)

Figura 6. Micrografias de MEV das misturas: a) PE91; b) PE73; c) PEA91; d) PEA73; e) PEPA91; e f) PEPA 73. 


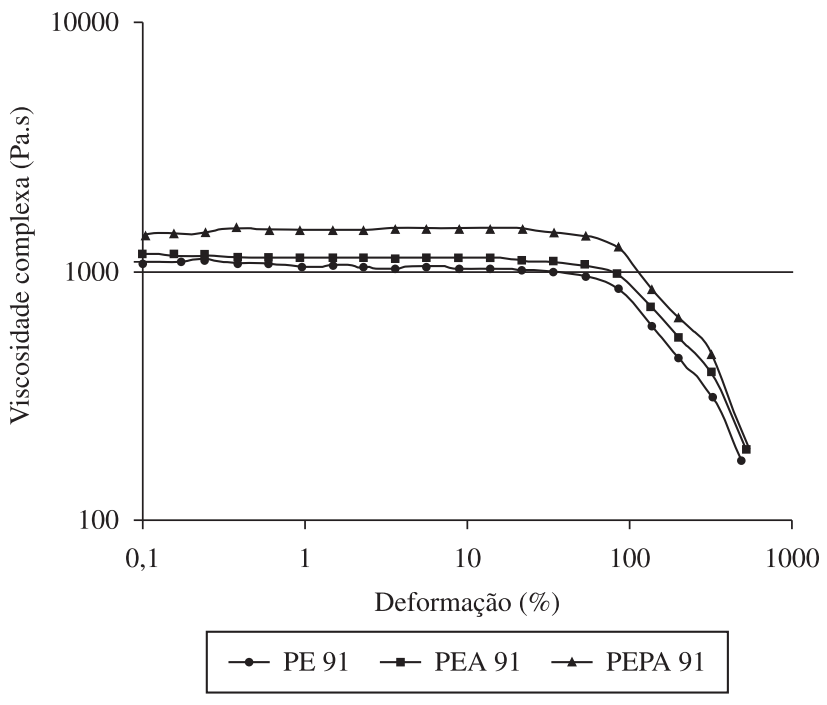

(a)

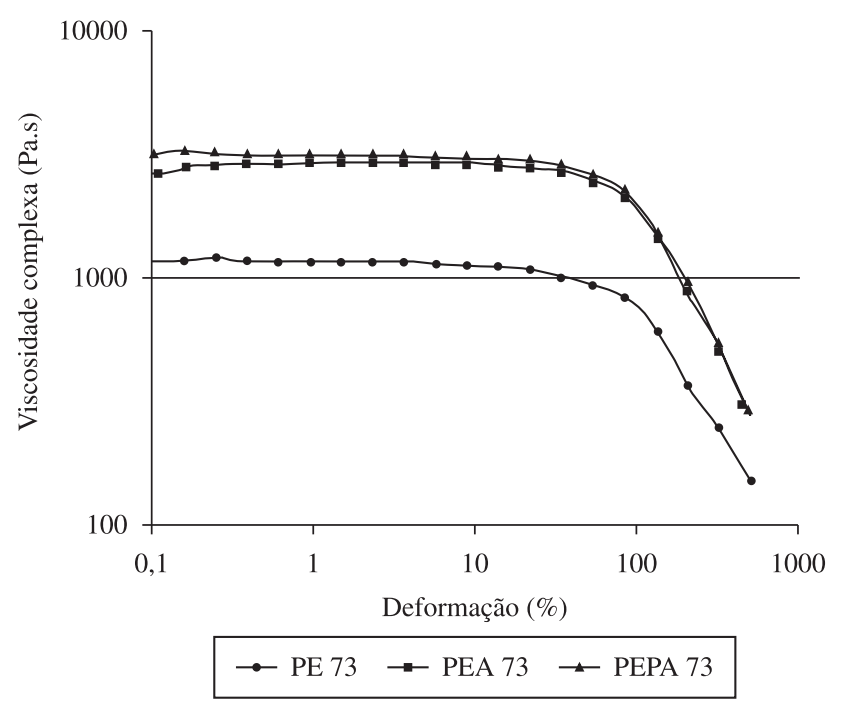

(b)

Figura 7. Viscosidade complexa das misturas: a) PE91, PEA91, PEPA91; e b) PE73, PEA73 e PEPA73.

Tabela 2. Varredura de frequência das misturas.

\begin{tabular}{ccc}
\hline Amostras & Frequência & $\mathbf{G}^{\prime}=\mathbf{G} \mathbf{G}^{\prime}$ \\
\hline PE 91 & 298 & 39831 \\
PEA 91 & 301 & 41330 \\
PEPA 91 & 198 & 38140 \\
PE 73 & 330 & 56721 \\
PEA73 & 139 & 48480 \\
PEPA 73 & 107 & 40180 \\
\hline
\end{tabular}

\section{Conclusões}

A incorporação de apenas 1 pcr de argila organofílica às misturas PP/EPDM e PP/EPDM/PP-g-MA resultou na formação de nanocompósitos poliméricos com estrutura desordenada. $\mathrm{O}$ teor de EPDM afetou a morfologia dos nanocompósitos obtidos. A argila organofílica atuou como agente compatibilizante para a mistura PP/EPDM, resultando no aumento das propriedades mecânicas das mesmas. O processo de compatibilização praticamente não foi alterado com a incorporação simultânea da argila APO e do PP-g-MA. Isto indica que a argila organofílica APO pode ser utilizada como agente compatibilizante inorgânico para estas misturas em substituição ao compatibilizante orgânico PP-g-MA, tradicionalmente usado para fortalecer a interface e estabilizar a morfologia das blendas PP/EPDM.

\section{Agradecimentos}

Os autores agradecem ao CNPq e a RENAMI pelo apoio financeiro, a Bentonit União Nordeste (BUN), a Braskem, DSM Elastomers Brazil e a Crompton Corporation pela doação da argila bentonita e dos polímeros.

\section{Referências Bibliográficas}

1. Gomes, A. S.; Barbosa, R. V. \& Soares, B. G. - Polímeros, p.19 (1992).

2. Dai, Y. Q.; Wang, B.; Wang, S. J.; Jiang, T. \& Cheng, S. Y. - Rad. Phy. Chem., 68, p.493 (2003). http://dx.doi.org/10.1016/S0969806X(03)00216-0

3. Bianchi, L.; Cimino, S.; Forte, A; Greco, R; Martuscelli, E.; Riva, F. \& Silvestre, C. J. - Mater. Sci., 20, p.895 (1985). http://dx.doi. org/10.1007/BF00585732
4. González, J.; Albano, C.; Candal, M. V.; Ichazo, M. N. \& Hernández, M. - Nucl. Instrum. Method. Phys. Research B: Beam Interac. Mater. Atoms., 236, p.354 (2005).

5. Karger-Kocsis, J.; Kalló, A.; Szafner, A.; Bodor, G. \& Sényei, Z. Polymer, 20, p. 37 (1979).

6. Tinker, A. J. - Polym. Commun., 25, p.325 (1984).

7. Nitta, K.; Kawada, T.; Yamahiro, M.; Mori, H. \& Terano, M. - Polymer, 41, p.6765 (2000). http://dx.doi.org/10.1016/S00323861(99)00895-2

8. Jang, B. Z.; Uhlmann, D. R. \& Vander, J. B. S. - J. Appl. Polym. Sci., 29, p.4377 (1984). http://dx.doi.org/10.1002/app.1984.070291266

9. Arroyo, M.; Zitzumbo, R. \& Avalos, F. - Polymer, 41, p.6351 (2000). http://dx.doi.org/10.1016/S0032-3861(99)00821-6

10. Jianga, W.; Tjonga, S. C. \& Lia, R. K. Y. - Polymer, 41, p.3479 (2000).

11. Pukánszky, B.; Tudos, F.; Kalló, A. \& Bodor, G. - Polymer, 30, p.1399 (1989).

12. Machado, M. A. L.; Biagiotti, J.; Arroyo, M. \& Kenny, J. M. - Polym. Eng. Sci., 43, p.1018 (2003).

13. Sirisinha, K. P. \& Preechachon, I. J. - Appl. Polym. Sci., 89, p.3557 (2003). http://dx.doi.org/10.1002/app.12544

14. Lee, H.; Fasulo, P. D.; Rodgers, W. R. \& Paul, D. R. - Polymer, 46, p.11673 (2005). http://dx.doi.org/10.1016/j.polymer.2005.09.068

15. Leaversuch, R. "Plastics Technology", 2009.

16. Ou,Y.;Guo,T.;Fang,X.;Yu,Z.-J.Appl.Polym.Sci.,74,p.2397(1999).http:// dx.doi.org/10.1002/(SICI)1097-4628(19991205)74:10\%3C2397::AIDAPP7\%3E3.0.CO;2-N

17. Mishra, J. K.; Hwang, K. J. \& Ha, C. S. - Polymer, 46, p.1995 (2005). http://dx.doi.org/10.1016/j.polymer.2004.12.044

18. Kim, D. H.; Fasulo, P. D.; Rodgers, W. R. \& Paul, D. R. - Polymer, 48, p.5308 (2007). http://dx.doi.org/10.1016/j.polymer.2007.07.011

19. Kim, D. H.; Fasulo, P. D.; Rodgers, W. R. \& Paul, D. R. - Polymer, 49, p.2492 (2008). http://dx.doi.org/10.1016/j.polymer.2008.04.005

20. Lee, H.; Fasulo, P. D.; Rodgers, W. R. \& Paul, D. R. - Polymer, 47, p.3528 (2006). http://dx.doi.org/10.1016/j.polymer.2006.03.016

21. Deshmane, C.; Yuan, Q. \& Misra, R. D. K. - Mater. Sci. Eng., 460-461, p.277 (2007). http://dx.doi.org/10.1016/j.msea.2007.01.045 
22. Mehta, S.; Mirabella, F. M.; Rufener, K. \& Bafna, A. J. - J. Appl. Polym. Sci., 92, p.928 (2004). http://dx.doi.org/10.1002/app.13693

23. Tjong, S. C. \& Ruan, Y. H. J. - J. Appl. Polym. Sci., 110, p.864 (2008). http://dx.doi.org/10.1002/app.28560

24. Leite, I. F.; Soares, A. P. S.; Carvalho, L. H.; Malta, O. M. L.; Raposo, C. M. O. \& Silva, S. M. L. - J. Thermal. Anal. Calorim., 100, p.563 (2010). http://dx.doi.org/10.1007/s10973-009-0265-3

25. Araujo, P. E. R.; Araújo, S. S.; Raposo, C. M. O.; Silva, S. M. L. "Poly(ethyleneterephthalate)(PET)/layered silicate nanocomposites. Effect of Bentonite purification on morpholog/behavior relationship", in: Proceedins of the 23th Polymer Processing Society Annual Meeting, p.1, 2007.

26. Silva, S. M. L., Araujo, P. E. R.; Ferreira, K. R. M.; Canedo, E. L.; Carvalho, L. H. \& Raposo, C. M. O. Polym. Eng. Sci., 49, p.1696 (2009). http://dx.doi.org/10.1002/pen.21399

27. Ray, S. S. \& Okamoto, M. - Prog. Polym. Sci., 28, p.1539 (2003).

28. Sánchez-Solís, A.; Garcia-Rejon, A. \& Manero, O. - Macromol. Symp., 192, p.281 (2003).

29. Marconcini, J. M. \& Ruvolo Filho, A. - Polímeros, 16(4), p.323, 2006.

30. Motamedi, P. \& Bagheri, R. - Mater. Des., 31, p.1776 (2010). http:// dx.doi.org/10.1016/j.matdes.2009.11.013

31. Dintcheva, N. Tz.; Filippone, G.; Mantia, F. P.; Acierno, D. - Polym. Degrad. Stab., p.527 (2010).

32. Filippone, G.; Dintcheva, N. Tz.; Mantia, F. P. \& Acierno, D. - Polymer, 51, p.3956 (2010). http://dx.doi.org/10.1016/j. polymer.2010.06.044

33. Petridis, D. \& Voulgaris, D. - Polymer, 43, p.2213 (2002). http://dx.doi. org/10.1016/S0032-3861(02)00039-3
34. Gelfer, M. Y.; Song, H. H.; Liu, L.; Hsiao, B. S.; Chu, B.; Rafailovich, M.; Si, M. \& Zaitsev, V. - J. Polym. Sci., Part B: Polym. Phys. 41, p.44 (2003). http://dx.doi.org/10.1002/polb.10360

35. Yurekli, K.; Karim, A.; Amis, E. J. \& Krishnamoorti, R. - Macromol., 36, p.7256 (2003). http://dx.doi.org/10.1021/ma0207551

36. Wang, Y.; Zhang, Q. \& Fu, Q. - Macromol. Rapid. Commun., 24, p.231 (2003). http://dx.doi.org/10.1002/marc.200390026

37. Khatua, B. B.; Lee, D. J.; Kim, H. Y. \& Kim, J. K. - Macromol., 37, p.2454 (2004). http://dx.doi.org/10.1021/ma0352072

38. Li, Y. \& Shimizu, H. - Polymer, 45, p.7381 (2004). http://dx.doi. org/10.1016/j.polymer.2004.09.018

39. Yoo, Y.; Park, C.; Lee, S.; Choi, K.; Kim, S. \& Lee, J. H. - Macromol. Chem. Phys., 206, p.878 (2005). http://dx.doi.org/10.1002/ macp. 200400526

40. Li, Y. \& Shimizu, H. - Macromol. Rapid. Commun., 26, p.710 (2005). http://dx.doi.org/10.1002/marc.200400654

41. Ray, S. S.; Pouliot, S.; Bousmina, M. \& Utracki, L. A. - Polymer, 45, p.8403 (2004).

42. Ray, S. S. \& Bousmina, M. - Macromol. Rapid. Commun., 26, p.1639 (2005).

43. Ray, S. S. \& Bousmina, M. - Macromol. Rapid. Commun., 26, p.450 (2005).

44. Hong, J. S.; Namkung, H.; Ahn, K. H.; Lee, S. J. \& Kim, C. - Polymer, 47, p.3967 (2006). http://dx.doi.org/10.1016/j.polymer.2006.03.077

45. Si, M.; Araki, T.; Ade, H.; Kilcoyne, A. L. D.; Fisher, R.; Sokolov, J. C. \& Rafailovich, M. H. - Macromol., 39, p.4793 (2006).

Enviado: 02/12/10

Reenviado: $14 / 03 / 11$

Aceito: $26 / 03 / 11$

DOI: $10.1590 / \mathrm{S} 0104-14282011005000072$ 